\title{
Classical University: Historical and Socio-Cultural Challenges and Development Trajectory Choice
}

\author{
Georgiy Ivanovich Gerasimov \\ Southern Federal University, Rostov-on-Don, Russian Federation \\ Email:Iarin41@mail.ru \\ Rashid Dumalichevich Khunagov
}

Adyghe State University, Maikop, Russian Federation

Fatima Kazbekovna Tuguz

Adyghe State University, Maikop, Russian Federation

Doi:10.5901/mjss.2015.v6n3s3p47

\begin{abstract}
The article considers the problem of the crisis of the classical university as a phenomenon of world educational practices and tendencies of the modern university, trying to adapt the founding of the university space to the new social conditions. The analysis of the different positions that characterize both the causes and the conditions to overcome the crisis of university education is given in the discourse of crisis. Particular attention is drawn to the possibility of conceptualizing the classical university through the reorganization of its ideas and mission under an objective trend towards verification of university education. Projective options for reconstruction of the grounds of classical university are analysed as one of the types of modern university, taking into account the transformation of modes of education and Russian specifics of the reforming higher education.
\end{abstract}

Keywords: classic university, diversification of types of the modern university; mission of the university, the idea of the university, modes of transformation of education

\section{Introduction}

In the face of global challenges of the XXI century, associated with the transition to a post-industrial society, a hallmark of which is the information technology revolution, accompanied by changes in various areas, including culture, the most important social institution, which introduces a fundamental need of the society in the development of personality adequate to modern social realities, is education.

Higher education performs a special role in this system, focused on the formation of a "society of knowledge", as it is the main resource and social mechanism for the reproduction of social intelligence. Today the transformation processes that characterize the changes of this social institution in Russia have clearly identified a number of trends, the effect of which is very controversial in its socio-cultural significance of the effects. In particular, dynamic massification and diversification of higher education, its momentary pointing pragmatic orientation (as immature social order), inevitably leads to conflict between the traditionally established and self-approved principles and values of university education and between these new social and cultural phenomena.

In these circumstances, universities now have and in the future will have to decide whether it will be focused primarily on the status and symbolic model of higher education. This is necessary for them "...to provide direct requests of production and applications of local scale (on the model of operational vocational training "according to the order") or the preparation of scientific, economic, political and cultural elite" (Dubinin, 2007).

In this regard, it should be noted that the Reformation efforts in Russian higher education in recent decades coincided with the indicated in the world practice trends, the main of which is the fact, which received the designation as the "crisis of the university". This phenomenon has a causal range and, in its most extreme, is purely catastrophic. On the one hand, it is a statement of fact - the "Western University died. It is hard to believe, but this is the reality. However, the history of the University talks about its extraordinary ability to innovate and adapt to the new conditions. This gives the 
hope that the miracle is happening now and will create a new university in future" (Barnett, Understanding of the University).

On the other, a small annotation to the book by Bill Ridings, which caused a considerable stir in the scientific community, under the catchy title "The University in Ruins", says that "the idea of the university has worked a long historical path: from the idea of reason (by Kant) through the idea of culture (by German idealists) and to the present idea of perfection and quality. But today, the university finds itself "in ruins", since none of the historical ideas can serve as the foundation of its existence" (Ridings, 2010). Describing the modern university as a "post-historic" type, B. Ridings denies such universities in the presence of any idea associated with the national framework of university culture. However, indicating the orientation of the activities of the "post-historic" university on maintaining the social order of multinational corporations in the form of the ideology of "high quality", he determines not the absence of the idea of the university as such, but only the shift of the ideological milestones, thus, contrary to his own statement (about the impossibility of the "quality" as the idea of the university).

Quite odious typing universities appear against the background of searching for new grounds, such as: "stony" century-old; "Ivory tower" - classical; "Observation tower" - forecast; "Entrepreneurial" - university-firm, etc. In other words, the university is changing not only its appearance, but also is being substantively transformed, getting into the force field of economic and socio-cultural transformations. Thus, diversification of education creates at least three groups of universities in the system of Russian higher education: classical, technical, and specialized. The entry into the market, according to some researchers and managers, adds to this differentiation the "entrepreneurial university" (Grudzinskiy, 2003) as well, while the change of priorities in the civilizational movement claimed for the "innovation university".

Thus, there is a real need in more thorough understanding of the trends that actually specify the vector and dynamics of the converting development as a whole system of higher education, in particular, its leading force - university education. In this case, first, it is a classical university, first, because of its historically special place in the destiny of world education, and, second, because it is its foundation, or rather the degree of compliance with the new social conditions civilizational development, are the subjects to the greatest doubt.

\section{Literature Review}

Problems of university education has significantly worsened in the background of updating the understanding of the present and the future of education systems in the modern era of the formation of information and intellectual civilization. Especially they are relevant to Russia, which made over the previous century an unprecedented leap in overcoming illiteracy, which created a system of compulsory education, but collided on the turn of the century with the threat of destruction of the existing system of education and a sharp drop in the level of both general and professional education of its citizens. It is a university education, which acts in the form of qualitative characteristics of the entire educational sphere of society. Therefore attention of the researches is predefined both to the understanding of the special role played by the university of the classic design in modern and contemporary culture of the time, and to how it is to be during the transition period to the new type of civilization, providing the future itself.

The genesis of the idea of the university is associated with the release of the three stages that characterize the image of the university and its educational space. These are "pre-classical", "classical", and "post-classical". Each of them is represented in the works, which became the intellectual basis of the material for the proposed article. However, special attention was paid to the works by Wilhelm von Humboldt, who laid the foundation of the actual university model, which became the classical one. The idea and the mission of the classical university became the subject of discussion in the famous lectures by G. Newman, and then, in the works by F. Schleimacher, J. Ortega y Gasset, and K. Jaspers. All of them in varying degrees made it possible to determine that the make-up of the new model of university was determined by European intelligence associated with the spread of culture, which was based on such notions as "rationality" and "right" (Karyes, 1996).

Traditions of discussing university education were continued by J. Habermas, J.-F. Lyotard, and Fuller, each of whom showed new contradictions, driving classic university to its post-classical state. These contradictions, which seemed to such researchers as R. Barnet and B. Ridings insoluble in educational and cultural framework of the classical university, led them to the conclusion about the "death" of the university in its current model. This situation is developed in the paper by M. Taylor named "Down with the university as we know it". Here he wrote off all the difficulties of the modern university to try to keep the fundamental principles of "Kant and Humboldt'"s University and the need to overcome this evil by providing university with the corporate nature (Taylor, 2009).

As for the Russian researchers of the university perspective, they are well represented in this article, covering almost the entire palette of the existing theoretical and methodological approaches: from the need for "revival" of value 
bases of the classical university, through its reconstruction based on the idea and the mission of the university, to complete rejection of the university model, incompatible with the modern conditions of educational organizations.

\section{Methodology}

Determining the theoretical and methodological basis of this work, the authors proceed from the understanding of the fact that the problem field of studying the genesis of classical university would require recourse to an approach that allows for overcoming the one-sidedness in the interpretation of ideas, mission and structure of the university, because there is a need to find the optimal resolution to the classical principle of single and universal base in the changing socio-cultural ontology. In addition, the understanding of education as a social and cultural phenomenon that goes beyond its limitations by metaphysical borders creates the need for accessing the capabilities of non-classical rationalism. Thus, the transdisciplinary approach was chosen to create a methodological construct adequate object of study, which allows for the synthesis of certain methodological paradigms, taking into account the specifics of the socio-cultural essence of education based on the neoclassical model of research. As is well known, it is characterised by updating the ideas of positivism, Marxism, and functionalism, based on consideration of nonlinear phenomena.

Neoclassical rationality, as well as classical one, is based on the principles of holism and empiricism. It suggests the possibility of objective cognition of social reality, as the interaction of certain systems and structures filled with specific socio-cultural meaning. In addition, its basic principles are as follows: realism, syncretism, theorization, pluralism, and reconstructionism.

Cognitive orientations of the research in the framework of the neoclassical paradigm are based on the necessity of overcoming the opposition of radical subjectivist and objectivist approach, the possibility of creating a coherent theory (through the synthesis of concepts) based on a "multi-dimensional" vision of social reality, the recognition of the methodological pluralism principle as the normal development of social sciences and humanities (which does not exist in the classical rationality).

\section{Results}

If we go back to the origins of the university education, it shall be recalled that the term "university" first appeared as the title of the law school in Bologna, founded in the $80 \mathrm{~s}$ of XI century. The foundations of the university organization were laid already in the first stages of forming the university system in XIII-XV centuries, when more than 80 universities appeared in Europe, among them: Paris (1200), Oxford (1206), Cambridge (1216), Naples (1224), and Lisbon (1290) Universities.

As for the classical university in the sense in which it existed to XX century, then it emerged, as many researchers believe, as a result of reforming the medieval university in the eighteenth century and is connected with the name of Humboldt, who, keeping the commitment to academic freedom as an organizing principle, laid the new principle of university education. It was not limited to the thorough study of the existing knowledge, but to the construction of the learning process based on fundamental research, "as for science growing from within and penetrating the human science only can transform the nature and the state, as the humanity is not that much interested in science and speeches, but rather in the nature and effect" (von Humboldt, 2000). It is this fact that contributed to the transformation of universities into academic centres, whose authority is largely determined by the quality of the research practice.

Moreover, the purpose of Humboldt's educational project "is not only the acquisition of knowledge by individuals, but also in the formation of a fully legitimate subject of knowledge and society" (Lyotard, 1988). That is, the characteristic feature of classical university was the fact that the process of education was not aimed at obtaining a ready knowledge, but at cognitive character of its search, the discovery of a method to acquire knowledge.

Essentially, the classical university reproduced the "unity of research and education, science and general education, science and enlightenment, and sciences among themselves" (Habermas, 1994).

On the other hand, at that time the basic contradiction of the organizational structure of the university were laid, as the governmental content of the university and university academic freedoms (the principle that came from the Roman law "what applies to all, must be approved by all"), inevitably created a conflict-prone soil of interaction. The conflict of interest is not only in the preservation of managerial autonomy of organization of the university community life, but also in the development of fundamental science with deferred pragmatic effect of its use, which is not always corresponds to the immediate interests of the state.

J. Newman, marking the birth signs of the classical university (universalism and non-utilitarianism) pays special attention to the nature of knowledge and the inherent nature of the university. In this case, there are two types of 
knowledge - versatile and utilitarian knowledge. If the first is extremely broad knowledge, not limiting consciousness with subject specialization, that is, the knowledge of the philosophical order, then the second one, striving toward the development of a particular craft, provides professional action (Newman J. H., 1996). Of course, the first type is actually the "university" knowledge, determining and determined by the mission of the classical university, embodied in the development of intellect and spirituality, providing aspiration to mastering and reproducing the culture. In its core, this interpretation of the mission indicates its socialising essence.

Since education ability of this (classical) model of the university is put in modern conditions in question, then, first and foremost, one shall look for the answer to the question "...if such a transformation of modern education, which will lead to a revival of a coherent fundamental educational system of Humboldt type, or if the basic features of the modern education has variability of pragmatism and, therefore, is the loss of opportunity to revive the fundamental educational system similar to the classic irreversible?" (Malakhov, On the possibility...). Then the author rightly points out that solution for this problem comes after analysing the status and trends of modern social and cultural space, in which the institute of education is functioning in order to identify the transformations that occur or are already taking place with the system or the institution of education.

From this point of view, if talking about transformation modes of the Russian high school, they can be presented by at least two groups, one of which describes the institutional and organizational changes (growth of educational institutions (EI), increasing the range of El types, diversification of higher education, democratisation of management systems, etc.); another - institutional and substantive changes (fundamentalisation, humanisation, continuity, information, etc.). Each of them generates its inherent group of contradictions.

With regard to the institutional and organizational changes, one shall note at least two trends, clearly manifested in the 90s of the last century. On the one hand of the attempts to actual, constructive diversification of higher education, where approaches to understanding the place and role of the university in the process of institutional transformation of education, it is possible to distinguish between the extreme points of view.

Some insist on the fact that "the debates shall concern only establishment of a truly powerful educational institution on a national scale, with resources to engage in a leading position in the training of new personnel. If talking about the creation of new institutions, a full-fledged university is required with a material and intellectual base non-precedent in Russia, or anything else is needed" (Pastukhov, 2007).

Other people, equally confident, witness that the "University often acts ...not as the engine and the model for development of the society: the rudiments of society, isolated and timid, are formed here besides and bypassing the University, for what the society, in fact, is offered to pay" (Dubinin, 2007).

Another group of people argues not without a reason that: "The centrepiece of any national system of higher education of the world for a long period of history is a large-scale multidisciplinary research Regional University (regional or national university, university of the state, land, etc.). These universities, in addition to solving common problems of higher education of the population, provide extremely expensive, research-based reproduction of scientific and pedagogical staff, which is essential for the existence of the entire education system as a whole" (Grudzinskiy, 2003).

It is possible to assume that at this stage, in the first approximation, the process is completed by the legitimization of the tiered structure of Russian university education - the two leading national Universities (MSU and SPbSU), a group of federal universities, as a kind of centre that can provide dynamic development of the Russian education system with access to the leading world level, the totality of university of research nature, etc. with legislative registration status positions. Here, the base of the system of verified university education is drawn, which can be typified by a substantive nature of the activities, the organization of scientific and educational space and principles of construction of the educational process.

On the other hand, these years are marked with a massive universitisation of the high school, inevitably giving the rise to substantial erosion of the intellectual, cultural, and educational framework of the concept of the "university". "If earlier the higher education was the school of aristocratic spirit, now it is reduced to the basic economic functions. Modern education does not educate, but produces, and in this sense is an integral part of the modern economy. This highly practical orientation significantly contributes to the erosion of the concept of the "university", turning it into a simple set of disparate institutions existing at the departmental level of some enterprise" (Gasilin, Crisis of classical...).

The result of this process, generating at least two negative trends, is obvious enough, and consists of the following trends:

- Implementation of a "strategy of stagnation", which, according to the Russian researcher T. L. Klyachko, is followed by more than a quarter of Russian universities (T. L. Klyachko, 2002).

- The degradation of the university, under which one shall "...understand such a change in its organization and key workflows, which leads to a decrease (is reflected in it) in objective indicators of its activity under the 
influence of external and internal factors" (Lisyutkin, Frumin, 2014);

- Among these factors are the following:

- Levelling the value of a university education as a policy of tolerance and political correctness has reduced the criteria for the selection of applicants, while university education cannot and should not be universal, it is intended for people with a scientific mind;

- Erasing the difference between a university researcher and a person with higher education, leading to the unification of their position, which leads to non-recognition of the university functions of forming the intellectual elite of society;

- Mass orientation to narrow specialization, designed to meet the needs of today, which impoverishes the university science and diverts the forces and means to solve immediate problems (Problems of academic freedoms...).

It is necessary to pay attention to the fundamentally different nature of the two steps of the above-identified trends.

Moreover, it is necessary to take into account the fact that from the very beginning universities were "a kind of centre of spiritual and intellectual power, the training centres of people in the spiritual core of society" (Shapovalov, 2005). This trend was particularly strong in Russia, where spirituality has always been a special honour and training of specialists was seen in terms of not only professional knowledge and skills, but also as a moral education, largely based on the individuality of a professor-mentor.

That is why "the idea of the university as it exists in the history of theoretical thought, always contains the meanings that cannot be reduced to uniformity of professional activity of population units. The university is regarded as a community of spiritually connected people, aware of their exclusivity and special mission in society. Not accidentally, the idea of the university is interpreted as the mission of the University" (Ogorodnikova, \& Goering, 2003). However, this idea has been lost in a series of reforms of shaping, more and more emasculating the spirit of the university.

Meanwhile, if talking about the crisis of classical university in his Humboldt sense, we should accept the fact that "...many of the basic principles underlying it no longer correspond to the current historical situation; we can turn to his main idea - the idea of universality - assuming the inextricable link of the all with many and knowledge of many through the all. We should not lose the humanistic message of the Humboldt project, which could also form the basis for the upcoming reconstruction" (Gasilin, 2013).

Here we shall separate the concept of "idea" of the university, which is, as rightly stressed by E. V. Strogetskaya (Strogetskaya, On the problem of identifying ...), strictly related to the type of university knowledge, as well as to the methods of working with them, as educational activities can be aimed at the production or accumulation of knowledge, from the concept of "mission" - the value-oriented and inherently generated university qualities of subjectivity of all those interacting in the educational space. In this case, the integrity of the structure and content of the educational process determine the compliance extent to which the idea and mission of the university. It is this integrity, which serves only possible response, according to which it is possible to determine the type of the University of the Totality, growing because of the diversification of university space and typology.

This is crucial, because the research field has a tendency to multiplication of the so-called "missions" on the principle of separation of all the variety of spheres of activity in the university. In particular, the "cultural mission of the university", "multicultural mission of the university", "civic mission of the university", "innovative mission of the university", "social mission of the university" and the like stand out and are investigated. There are debates concerning the problem of definition and methodology for assessing the "third mission" of the university" (Marhl,\& Pausist, 2013), based on market realities and the ideology of continuing education as not the "education for the entire life", but as the "education throughout life".

In all likelihood, this kaleidoscopic variety of the so-called "missions" reflect the ability, which, according to R. Barnett, can act as a new mission of the modern university - to become the beginning of an integrating society, losing its integrity (Barnett, 1999). However, it is necessary to find the most unifying principle, which ensures the integrity of the mission, in contrast to the variety of functions of the university.

For better identification of the problem of establishing the modern university, it is important not only to trace the genesis of the idea of the university and its mission, but also to answer the question: "What is the basis of the university as an institution of special education?". This is how a very relevant question for our time is put by J. S. Weiland. He writes: "Of course, we know about the existence of an institution called "university", but - and this is the whole question is this institution really a university? Having visited numerous colleges, libraries, museums, laboratories and similar departments, each person who does not want to fall into the category mistake may ask: "But where is the university itself? " (Weiland, 1991). This is a particularly relevant issue for the Russian system of higher education, which, as has been said, in the last decade passed a not very simple way of "universal universitezation" in the form of a parade of 
changing signs, but without changing the content of the essential part of the organization of educational space.

The answer to this question about the actual university can be considered the opinion of the German philosopher Karl Jaspers: "University is a place where, due to the conditions created by the state and society, self-consciousness of the era is cultivated... Consequently, the problem of the university is threefold - research, knowledge transfer (education) and culture. Each of these edges, considered in itself, cannot be separated from the other two" (Shapovalov, 1996). It is here where the idea and the mission of the modern university are overlapping and expressed.

Thus, one of the reasons that bring together the idea and the mission of the classical university with its neoclassical successor seeking their place in a variety of modern university space can be considered a quite pragmatic desire for such a learning process, which helps to overcome "specialism and professionalism", these indispensable companions of industrialism. According to Ortega y Gasset, they "..."break into pieces" a European human being, as they represent only a narrow sphere of life. In this situation, the task of the university is to return this vital unity, resuming transmission of culture, i.e. of living ideas disposed by the time" (Ortega y Gasset, 1999, 68).

In other words, it is the question of understanding education as a social and cultural phenomenon, paradigmatic foundation of which is reproducing in the new environment both the principle of universality, and humanistic message of classical university. In this case, its general scientific bases may be co-evolution of natural, social and cultural systems, replacing the paradigm of "domination" of a human being over nature, society and himself, which in turn allows building relationships between people, communities, groups, ethnic groups, etc. based on the culture of dialogue and consent, reconciliation of diverse interests, tolerance for pluralism of values, but not omnivorous and moral chaos.

University education is presented as an open system (based on the principles of systemacity, uncertainty and randomness, information fundamental principle of the organized matter) of anticipatory order aimed at "the production of the Future" with the functional purpose of stabilizing the development. Consequently, its main characteristics are openness to the future, advanced character, continuity, and projective defining the prospects for development.

Interaction of the structural elements of the system is based on the reorientation of educational values in the content of educational systems to the fundamental scientific instruments humanistic nature, contributing to design the readiness to the educational action of subjective nature as to conscious and purposeful process.

The distinctive mark of this system is the ability of education to preserve, transfer, and develop semantic coordinates of culture. The generated ability of the person and the educational system-created opportunity to give birth to adjust itself as the backbone principles, create the conditions for breeding subjectivity up. The dialectic of these parties determines the effectiveness of the disclosure of the potential pf the socio-cultural education.

Thus, it is not about the "revival" of the classical model of Humboldt's university, but about its reconstruction, which can be described as a transition to the neoclassical model of university with cultural and educational space correlating both with the initial premises of high culture, and the ability to meet the needs of the representative culture, bringing it closer to the deep level of performance culture. By means of variant modes of base values of culture through educational ideal, value-target regulative and content of the educational process, there is a coordination of the subjective and the objective reality with individual goals and meanings. In this case, the educational process acts as a kind of social interaction, the content of which is the exchange of information, rationally implemented in the reproductive system of social and cultural relations of society.

This type of education is implementing modern educational paradigm (Gerasimov, Lubskiy 2014), since it allows providing conditions for the transition from the translation and assimilation of hard-coded rules to creation of the conditions for the personal development of the individual educational texts, in which a greater or lesser proportion of disordered meanings, values and patterns of behaviour creates opportunity to: master the existing codes of culture in their contradictory diversity and dynamics; compare them based on their own experience of the individual with the objective social reality, personal goals, values, needs, and opportunities; learn not only how to use certain elements of culture, but also to come in the form of intellectual or behavioural modelling at the level of their changes.

Regularity of transition to a new type of socio-cultural education is determined by the need to restore the mismatch between the codes of culture, which are translated in the educational process, and those programs of individual and group behaviour that objectively provide the optimal level of adaptation of individuals and communities of people. A qualitatively new nature of social and cultural relations of the information society puts the theory and practice of education to the need to develop the conceptual foundations of the design of the educational process, adequate to modern conditions.

In general, taking this approach as one of the most constructive, we note that, starting from the characteristics of the educational process and, building on this logic, all subsequent moves; it is possible to lose the sociocultural dimension frame, which should be related not so much with the aim, but to the result. No wonder one of the well-known researchers in the field of philosophy of education, N. S. Rozov in determining the purpose of education, attracts attention 
to what shall be the product of education. This is not about pedagogy adopted in the descriptions of the "model of the graduate" with a large list of knowledge and skills, and in the best case - of social qualities.

Socio-philosophical measure of the "product" is the balance "...in the orientation of education to the Human Being, Society, and Culture. We - continues on N. S. Rozov, - will add this idea of balance with the concept of cultural models (A. Kroeber) and system-wide views on reproduction and development (G. P. Schedrovitskiy). In this case, education shall be directed to the reproduction and development of the Culture (as the system of samples), the Society (as the embodiment of social patterns of culture in public institutions, structures, relationships, processes), and the Human Being (as a carrier of anthropic samples of culture)" (Rozov, 1993).

It is likely that this provision shall be strengthened by the fact that the balance (harmony) shall be focused on giving the culture forming, not just cultural conformity nature to the whole system and the process of interaction of the system's subjects.

\section{Discussion}

Thus, analysis of trends, defining the role and place of the classical university in terms of verification of university education from the standpoint of the possibility of its "revival" in response to the historical and socio-cultural challenges, makes it possible to argue that the choice of the path for the development of university education in the transformation of the Russian education system is connected to the following:

First, to understanding the need for reconstruction of classical university as an integral cultural and educational space, which is building the conditions for "breeding up" intellectual and cultural elite, aware of its civil liability, being the core of the emerging creative class (Yu. G. Volkov, 2013);

Second, to rethinking the interpretation of ideas and mission of the university, with all possible variations of preserving orientation to the fact that the development of intellect and spirituality is and continue to be as the ultimate goals of university education, the only meeting of its nature (J. H. Newman, 1996);

Third, to the adoption of the fact of row-type coexistence of different types of universities (including classical) and models posing itself on the classical, neo-classical, and postmodern grounds.

\section{References}

Anrich, E. (1956). Die idee der Deutschen Universitat. Die funf Grundschriften aus der Zeit ihrer Neubegrundung durch klassischen Idealismus und romantischen Realismus. Darmstadt: Wissenschaftliche Buchgesellschaft.

Barnett, R. (1999). Realizing the university in an age of supercomplexity (p. 97). Buckingham: Open Univ. Press.

Barnett, R. Understanding the University. Education in contemporary culture. No. 1. Retrieved from: http://charko.narod.ru/tekst/ alm1/barnet.htm

Donoghue, F. (2008). The Last Professors: the Corporate University and the Fate of the Humanities. N.Y.: Fordham University Press.

Dubinin, B.V. (2007). Russian universities (Lessons from the past and challenges for tomorrow). Social studies and the present time. No. 1.

Gumboldt, K.V. (2000). On the internal and external organization of higher academic institutions in Berlin. Current strategies of cultural studies. Vol. 1.

Klyachko, T. L. (Ed) (2002). Adaptation strategies of higher education institutions: Economic and sociological aspects. M.: SU HSE.(Series "Library of Education").

Fuller, S. (2004). Karl Popper and the reunification of the left rationalism (p. 123-124). Problems of Philosophy. No. 7.

Gasilin, A. (2013). The crisis of the classical university: degradation or reconstruction. Retrieved from: http://andrey-gasilin.livejournal. com/88903.html

Gerasimov, G.I. \& Lubskiy, A.V. (2014). Dialogues on higher education: a paradigmatic approach and developing-cognitive paradigm of education. Rostov-On-Don.

Grudzinskiy, A.O. (2003). University as an entrepreneurial organization. Sociology of education facing the new challenges. Moscow, Omsk.

Habermas, J. (1994). The idea of a university. Processes of education / J. Habermas; short. trans. from German by A. Yarina. Alma mater. No. 4.

Jaspers, K. (1980). Die Idee der Universitat. Berlin: Springer.

Karyes, G. (1996). The cultural models of the university. (p. 28-32) Alma mater. No. 3.

Kerr, C. (1982). The uses of the university. Cambridge, Mass.: Harvard University Press.

Lehmann-Carli, G., Schippan M., Scholz B., Brohm S. (hrsg.). (2001) Aufklärungrezeption und Bildungskonzepte in Russland. Russische Aufklärungsrezeption im Kontext offizieller Bildungskonzepte (1700-1825). Berlin, S. IX-XXXVI.

Lisiutkin, M.A., Frumin, I.D. (2014). How do universities degrade? By the statement of the problem (P. 14). University Management: Practice and Analysis. No. 4-5. Retrieved from: http://umj.ru/index.php/pub/inside/1570/ 
Lyotard, J.-F. (1998). Postmodern condition. M.; SPb.: Aletheia.

Marhl, M. \& Pausist, A. (2013). Methodology of assessment of the "third mission" of universities. Continuing education: XXI century. Vol. 1. No. 1 (1).

Newman, J.H. (1996). The idea of university. (P. 83-84) New Haven, CT: Yale Univ. Press.

Ogorodnikova, I.A. \& Gering, A.G. (2003). The idea of the university - the project for the perfect embodiment of the educational form. Sociology of education facing the new challenges. Moscow, Omsk.

Ortega y Gasset, J. (1999). Mision de la Universidad y otros ensayos sobre education y pedagogfa. Madrid: Revista de Occidente.

Pastukhov, V. B. (2007). The concept of "ideal university" as a kind of Russian national utopia. Social sciences and the present. No. 1.

Ridings B. (2010) University in ruins. M.: Publishing House of the State. Univ - Higher School of Economics.

Schnedelbach, G. (2002). Humboldt University. (p. 65-78). Logos. No. 5-6.

Shapovalov, V. A. (2005). The mission of the university. Higher education in Russia. No. 9.

Strogetskaya, E. V. On the problem of identifying the social mechanisms of the university. Round table: Modernization of education: ideas and practices. St. Petersburg. Retrieved from: http://www.ssa-rss.ru/abstract_bank/1251185449.pdf

Taylor, M.C. (2009). End the university as we know it. The New York Times. April 26.

Volkov, Yu.G. (2013). Creativity: creative work against imitation. M.: Alfa-M, Infra-M.

Weiland, J.S. (1991) Universities and the new face of Europe. Bulletin of higher education. No. 4. 